\title{
Medical Interns' Perceptions about Disclosing Medical Errors
}

\author{
Sedigheh Ebrahimi, ${ }^{1}$ Seyed Ziaedin Tabei, ${ }^{1}$ Fatemeh Kalantari, ${ }^{1}$ and Alireza Ebrahimi $\mathbb{D}^{2}$ \\ ${ }^{1}$ Department of Medical Ethics, Shiraz University of Medical Sciences, Shiraz, Iran \\ ${ }^{2}$ Student Research Committee, Shiraz University of Medical Sciences, Shiraz, Iran \\ Correspondence should be addressed to Alireza Ebrahimi; alireza.ibrahim92@gmail.com
}

Received 8 June 2021; Accepted 18 August 2021; Published 25 August 2021

Academic Editor: Connie M. Wiskin

Copyright (c) 2021 Sedigheh Ebrahimi et al. This is an open access article distributed under the Creative Commons Attribution License, which permits unrestricted use, distribution, and reproduction in any medium, provided the original work is properly cited.

\begin{abstract}
Background. Honest and timely reporting of medical errors is the professional and ethical duty of any physician as it can help the patients and their families to understand the condition and enable the practitioners to prevent the consequences of the error. This study aims to investigate the viewpoints of medical interns regarding medical error disclosure in educational hospitals in Shiraz, Iran. Methods. A researcher-made questionnaire was used for data collection. The survey consisted of questions about the medical error disclosure, the willingness to disclose an error, the interns' experiences and intentions of reporting the medical error, and two scenarios to assess the students' response to a medical error. Results. Medical interns believed that a medical error must be reported for the sake of conscience and commitment and prevention of further consequences. The most important cause of not reporting an error was found to be inappropriate communication skills among the students. The results indicated that the willingness to disclose the hypothetical error among females was more than males $(R<0.005)$, but in practice, there was no difference between males and females $(R>0.005)$. The willingness to disclose minor and major hypothetical errors had a positive correlation $(P<0.001, R=0.848)$. Conclusion. More ethical training and education of communication skills would be helpful to persuade physicians to disclose medical errors.
\end{abstract}

\section{Background}

The definition of a medical error (ME) has been changed over time and may be different according to different situations and purposes [1]. ME is a deviation from the care protocol that may or may not result in harm to the patient [2]. Also, an unplanned action (both commission and omission) or an act that does not succeed in the intended result is a ME [3]. In the present study, we considered ME as "the failure of scheduled actions to achieve the expected goals, a mistake in planning, or deviating from the care process, which can cause harm to the patient," according to Reason's and Leape's definition [2-4], while as mentioned above, several factors such as legislation, ethics, quality control, legal action, and legislative regulation can determine the ME definition. Thereupon, more efforts and investigations are needed to construct a standardized terminology that could be universally accepted [1].

MEs and adverse events related to MEs are among the significant concerns of healthcare systems $[5,6]$. ME is considered among the major causes of morbidity and mortality globally, whereas it seems to be more common in developing countries such as Iran where the overall prevalence of MEs was estimated to be $50 \%[7,8]$. Moreover, MEs and the related adverse events could cause several medical disabilities and are the main reasons of accumulating complaints in hospitals $[9,10]$. The errors might prolong the inpatient services and result in death in some cases [10]. MEs could occur because of burnout of the healthcare workers, lack of medical knowledge and job experience, absence of communication between the workers, and inadequate supervision [11-13]. Nevertheless, finding consistent causes of the errors and providing practical solutions are challenging tasks as the errors may occur because of several personal, interpersonal, and systemic factors [14]. In this regard, the healthcare professionals' attention to the patients' safety has remarkably grown over the past decades [15]. However, some physicians are still unaware of the scope of the problem, the burden on healthcare systems, the impacts on patients, and the strategies to reduce the risk of harm of MEs [15]. 
The treating physicians may encounter punishments and penalties for their failures, which may be formal (organization-imposed) and informal (psychological and social) [16]. In Iran, the Medical Council identifies errors made by physicians and investigates them against published guidelines. The legal division of the Medical Council might find the physicians responsible for the harm caused by ME and might rule for the compensation according to Shariah principles. Furthermore, the litigation of ME in Iran may include payment for compensation and temporary or permanent suspension from professional services. In the private sector, the physician is personally responsible for any $\mathrm{ME}$ if he/she fails to exercise the standard of care and treatment [17]. In the public sector, the most senior physician of the treating team is recognized to be responsible for the ME [18]. However, in this respect, medical constituents have several flaws in many countries, especially in developing regions $[17,19]$. For example, in some cases, the physicians may be convicted to be arrested and taken to a police station and even to serve a prison sentence by a judiciary which lacks the related medical knowledges [19]. The legislators must mention these problems that may lead the public to lose their respect for healthcare systems.

Following a ME, the clinicians who were involved, preferably the senior ones, should inform the patients or their families - if consented-about the error, how it will be relieved, and further therapeutic responses [20, 21]. Furthermore, a sincere apology and an expression of regret must be made to the harmed patients [22, 23]. Appropriate and honest disclosure of MEs helps the physicians to regain the patients' trust and respect, decrease the chances of litigation, and can mitigate the harm $[24,25]$. Furthermore, truthful ME disclosure is a physician's responsibility and duty that helps them to keep their professional integrity $[20,26]$.

In contrast to the above fact, statistics demonstrated that disclosing MEs has been perceived as an ethical challenge for many clinicians, and they commonly reticence to reveal the harm [27-29]. In this regard, previous studies mentioned that reporting the errors is inefficient in Iran, and nondisclosure of MEs is a common problem, especially in teaching hospitals [30]. This could be because of the historical dichotomy between doctors' paternalism and patients' autonomy that has continued on this matter [24, 31]. Previous studies also mentioned several ethical, social, psychological, and practical barriers to disclose the ME [32-34]. Cultural issues, lack of communication skills, legal and regulatory impediments, and absence of institutional support have been mentioned to be among the barriers to report MEs [34, 35].

Several strategies have been proposed for ME disclosure to achieve the purpose of the disclosure, which mostly include the following two stages. Firstly, the patients must be informed about the error, the potential consequences, and available cures for the condition [36]. Then, the clinicians must apologize to the harmed patients and provide the patients with information about the future attempts to prevent recurrence of the event [36]. Considering the available guidelines for disclosing MEs, the policy of the United States Joint Commission on Accreditation of Healthcare Organizations has the least flaws [37].
Many clinicians firstly encountered the ME and experienced ME disclosure in the early years of training [38]. Previous studies mentioned that nearly four-fifths of fourthyear medical students and medical interns have faced with MEs [39]. Many of the medical trainees reported that these errors must be disclosed with the harmed patients, though, in contrast to this belief, they had not been fully disclosing the errors [38]. This could be due to the above barriers to disclose MEs and could result in future incompetency. Currently, a few medical schools implement ME disclosure training curricula, whereas a lack of comprehensive and globally accepted curriculum is apparent. Evaluating the intraining physicians' attitudes and perceptions regarding the $\mathrm{ME}$ disclosure is required to improve the relevant curricula. This study aims to investigate both attitudes and actual clinical responses of medical interns at a major Iranian medical school and public teaching hospitals regarding $\mathrm{ME}$ disclosure. We aimed to advance the discussion initiated by prior studies of the experience of medical interns with MEs.

\section{Materials and Methods}

2.1. Population and Data Collection. This descriptive-analytical, cross-sectional, and hospital-based study was performed between 2015 and 2016 in Shiraz Medical School, Shiraz University of Medical Sciences, Shiraz, Iran. Of the total 217 medical interns, 160 agreed to participate in the investigation and were selected as samples. The study took place at Namazi, Shahid Faghihi, Hafez, and Ebnesina hospitals, in which all of them are public institutions. It is noteworthy that the prevalence of MEs was calculated to be $69.7 \%$ in Shahid Faghihi hospital and that $89.4 \%$ of these errors were minor or near-miss ones [40]. The data gathering tool was a researcher-made questionnaire that was designed after a review of the existing literature with similar research titles (Persian and English sources) [31, 39, 41, 42].

The questionnaires were distributed to the interns on different occasions such as morning sessions, patient rounds, and via the internet (e-mail). The interns were asked to independently fill out the surveys by recalling the most prominent error encountered during their clinical clerkship and return the surveys at the earliest. Data were extracted, and an initial analysis was done. The finalized data were sent for statistical evaluations.

2.2. The Questionnaire. An introduction was written for the questionnaire, discussing the definition of the $\mathrm{ME}$, the impact of the ME on both patients and physicians, and types of ME including minor and serious errors. ME was defined as the failure of a planned action to be accomplished as anticipated or implementing an incorrect strategy to complete a purpose. Minor error was described as an error that leads to an injury that is neither long-lasting nor lifethreatening. Serious error was considered as an error that results in a lasting injury or fatal harm.

The questionnaire consisted of five sections (53 questions). The first part of the inquiry gathers demographic information. The second and third parts include questions 
about the interns' experiences regarding the $\mathrm{ME}$ and $\mathrm{ME}$ disclosure. The fourth part is based on Likert-scale grades (totally agree $=5$ and totally disagree $=1$ ) and includes 32 questions that evaluate the interns' agreement and commitment on disclosing MEs. To assess this part of the survey, the total scores were measured between 48 and 132 (48 is the least possible commitment, and 132 is the most). Finally, in the fifth section, two scenarios were designed to achieve the interns' attitudes and knowledge about ME disclosure; and the interns were asked to end these scenarios. The first scenario was designed considering the previous investigations about the significant MEs, and the second scenario was based on the most prevalent errors in the local hospitals.

To evaluate the face and content validity of the questionnaire, an expert panel, including two postdoctoral researchers and two professors of the Medical Ethics Department, evaluated the questionnaire before the pilot testing of the survey. The recommendations about the level of difficulty, the degree of relevancy, and the ambiguity of the expressions were considered for the revision of the survey. Then, the revised questionnaires were completed by 40 people of the target group to evaluate the quantitative face validity. The quantitative face validity of the survey was calculated using the formula of the item impact method. Two scenarios were presented at the end of the questionnaire to examine the content validity of the survey. In order to evaluate the reliability of the questionnaire, it was given to 30 internal medicine residents and 10 medical interns who were selected randomly. After a month, forty questionnaires were given to the same people. The questions which were not appropriately consistent according to the tau-equivalent reliability test were omitted $(\rho \tau<0.7)$. The outcome was also evaluated by the Pearson correlation test, which showed that the survey has prominent reliability $(R=0.83)$. The consensus of the expert panel was achieved on the validity and reliability of the survey before the initiation of the study.

2.3. The Scenarios. A: a 68 -year-old male patient has been admitted to the Coronary Care Unit due to atrial fibrillation. The cardiologists stabilized the patient and controlled heart rate by emergent interventions. Hence, heparin and warfarin were prescribed for the patient. The patient's hemodynamic status was secured, and the international normalized ratio (INR) reached to the accepted level (2-2.5). The attending physician discharged the patient of the service, and the resident physician asked one to write and order a prescription and recommendation for the patient as one tablet of warfarin once daily, check prothrombin time (PT) and INR every three days, and an outpatient visit in 2 weeks. A week later, the patient returned to the emergency department with a large and painful hematoma in the thigh area and an INR of 14.7 .

B: in the pediatric ward, a 4-year-old girl with chronic granulomatosis is hospitalized with a diagnosis of the left knee septic arthritis. The attending physician had ordered magnetic resonance imaging (MRI) of the left knee. In the request form, one wrongly wrote MRI of the right knee, and the MRI was incorrectly performed for the patient.
2.4. Data Management and Statistical Analysis. Data were reviewed for accuracy and were verified by two independent statisticians. Descriptive statistics were analyzed using mean, variance, and percentage calculation. Pearson correlation test was used to find the association between categorical variables. Inferential variables were also compared using the chi-square and two-tailed $T$-tests. We considered differences with a $P$ value $\leq 0.05$ as statistically significant. The tauequivalent reliability test was also used to evaluate the reliability of the survey and the questions. Statistical analyses were performed using SPSS version 22.0 (SPSS Inc., Chicago, IL).

2.5. Ethical Considerations. Before the initiation of the investigation, the purpose and nature of the research were explained to the participants. Participation in this study was voluntary, and the questionnaire, if consented, was given to be completed. Anonymity and secrecy of information of the participants were also provided. Additionally, the questionnaire did not ask the respondents' name in order to maintain confidentiality.

The interns have voluntarily participated in this study, and they were assured that their filled data would be kept confidential. The information sheets were anonymously labelled with a code number for each participant. Raw data were generated at the research office of the Department of Medical Ethics, and derived data were then sent for statistical analysis. All datasets used and/or analyzed during the current study are stored at the research office and archived for ten years from the date of publication.

\section{Results}

160 out of the 217 distributed questionnaires were completed by the participants (73\% response rate). Among the participants, 86 (53.8\%) were female, and 74 (46.2\%) were male, 17 (10.6\%) were married and 143 (89.4\%) were single. Furthermore, $58(36.2 \%)$ of the participants were passing the first six months of the medical internship program, 69 $(43.1 \%)$ were in the second six months of the program, and $33(20.6 \%)$ were senior medical interns (last six months of the program). All of the participants were Muslims; among them, 39 (25\%) had radical religious beliefs, $104(66.7 \%)$ were moderate, and $13(8.5 \%)$ had unconvinced faith. The demographic characteristics of the participants are shown in Table 1.

Table 2 presents the interns' exposure to minor and serious MEs. 107 (67.3\%) and 149 (93.1\%) of the interns have encountered with at least a serious $\mathrm{ME}$ and a minor ME, respectively.

Considering the serious MEs, 33 (20.9\%) said that they would report, 100 (63.3\%) mentioned that they might report, and $25(15.8 \%)$ said that they would not report the error. These numbers were 49 (31.8\%), 79 (51.3\%), and $26(16.9 \%)$, respectively, regarding the minor MEs. A significant twotailed correlation was found between reporting the minor MEs and serious MEs. The interns that report minor MEs tend to report the serious ones as well, and vice-versa $(P$ 
TABle 1: Demographic data of the participants.

\begin{tabular}{|c|c|c|}
\hline Variable & Status & Number (percentage) \\
\hline \multirow{2}{*}{ Sex } & Male & $86(53.8)$ \\
\hline & Female & $74(46.2)$ \\
\hline \multirow{3}{*}{ Medicine internship program (18 months) } & $1^{\text {st }}$ six months & $33(20.6)$ \\
\hline & $2^{\text {nd }}$ six months & $69(43.1)$ \\
\hline & $3^{\text {rd }}$ six months & $58(36.2)$ \\
\hline \multirow{2}{*}{ Marital status } & Single & $143(89.4)$ \\
\hline & Married & $17(10.6)$ \\
\hline \multirow{3}{*}{ Religious belief } & Radical Muslim & $39(25)$ \\
\hline & Moderate Muslim & $104(66.7)$ \\
\hline & Unconvinced Muslim & $13(8.3)$ \\
\hline \multirow{3}{*}{ Medical ethics courses about error disclosure } & Completed & $60(37.7)$ \\
\hline & Somehow completed & $66(41.5)$ \\
\hline & Uncompleted & $33(20.8)$ \\
\hline \multirow{3}{*}{ Sufficiency of medical ethics courses about error disclosure } & Adequate & $14(8.9)$ \\
\hline & Somehow adequate & $69(43.7)$ \\
\hline & Inadequate & $75(47.5)$ \\
\hline
\end{tabular}

TABLe 2: Types of medical error and the rate of exposure.

\begin{tabular}{lcc}
\hline Type of medical error & $\begin{array}{c}\text { Encountered } \\
\text { Number (percentage) }\end{array}$ & $\begin{array}{c}\text { Not encountered } \\
\text { Number (percentage) }\end{array}$ \\
\hline Serious medical error & $107(67 / 3)$ & $52(32 / 7)$ \\
Minor medical error & $149(93 / 1)$ & $11(6 / 9)$ \\
\hline
\end{tabular}

value $<0.001)$. Moreover, $74.7 \%$ of the interns completely or partially agreed on the policy that asserts ME disclosure should also be prepared in written forms. Table 3 demonstrates the interns' willingness to report minor/serious MEs.

During the clinical clerkship, 59 (36.9\%) of the interns made at least one minor error, $52(32.5 \%)$ had made at least one serious error, and any medical error did not challenge 49 $(30.6 \%)$ of them. In this regard, $63.8 \%$ of the interns who made minor errors had disclosed the errors, and $73.5 \%$ of the participants who made serious errors had reported their mistake. Moreover, $47.1 \%$ of them asserted that they adequately managed and reversed the side effects of the medical error, and $41.1 \%$ have expressed that the reason for their disclosure was to reduce the risk of future errors. The interns' experience of ME disclosure after making a serious or minor error, their involvement in evaluating and managing the error, and they preventing the adverse effects of the error are demonstrated in Table 4. No significant association between the interns' type of error and the probability of ME disclosure $(P$ value $=0.284)$ was found.

The designed scores of the 5-point Likert scale that evaluates the probability of ME disclosure were between 48 and 132. The mean score for all the interns was measured to be $96.7 \pm 18.3$. The mean score was calculated as $101.63 \pm 16.73$ and $91.38 \pm 18.55$ for female and male participants, respectively. There was a significant difference regarding the scores of the probability of ME disclosure between female and male interns $\left(P_{\text {minor MEs }}=0.039\right.$ and $\left.P_{\text {serious MEs }}=0.015\right)$. Our study also showed a significant correlation between the participants' religious belief status and reporting minor MEs; the interns with stricter religious beliefs were more tended to report the error $\left(P_{\text {minor MEs }}=0.01\right.$ and $\left.P_{\text {serious MEs }}=0.065\right)$.
No significant association was found between the marital status and $\mathrm{ME}$ disclosure scores $\left(P_{\text {minor MEs }}=0.932\right.$ and $P_{\text {serious MEs }}=0.267$ ).

The interns believed that medical error disclosure is a sign of physicians' consciousness and morality (mean score $=3.81 \pm 0.91)$ and helps them to keep their professional integrity (mean score $=3.68 \pm 1.03$ ). They also believed that timely reporting of the medical error could help the physicians to manage and reverse the adverse effects of the error (mean score $=3.45 \pm 1.08$ ). The interns mentioned that the ME could affect both physicians and patients (mean score $=3.44 \pm 1.06$ ); besides, the patients have the right to be informed about the errors (mean score $=3.92 \pm 0.88$ ). However, some interns said that the healthcare system should be blamed for any $\mathrm{ME}$, and the physicians are not responsible on this matter (mean score $=3.71 \pm 1.10$ ). Some thought that there is no need to disclose the errors as they are inevitable (mean score $=3.11 \pm 1.25$ ), and the physicians should only apologize to the patients-without any further action-after the occurrence of an error (mean score $=3.30 \pm 1.04$ ). Some others believed that there is no need for medical error disclosure; however, it must be compensated (mean score $=2.54 \pm 1.17)$. The interns mentioned that fear of litigation (mean score $=2.33 \pm 0.96$ ), losing esteem (mean score $=2.82 \pm 1.16$ ), and institutional penalties (mean score $=2.30 \pm 1.20)$ are among the reasons for not disclosing MEs. Moreover, some of the interns preferred not to disclose MEs as they assumed that the patients might not properly understand the situation (mean score $=2.07 \pm 1.04$ ) and dangerously overreact to the problem (mean score $=1.83 \pm 0.86$ ). Lack of communication skills (mean score $=3.28 \pm 1.08)$ and knowledge $($ mean score $=3.08 \pm 1.08)$ 
TABLE 3: The interns' willingness to report the medical error.

\begin{tabular}{|c|c|c|c|}
\hline \multirow[b]{2}{*}{ Type of error } & Willingness to repc & the error & \multirow[b]{2}{*}{$\begin{array}{l}\text { Correlation between the type of hypothetical error and willingness to } \\
\text { comment }\end{array}$} \\
\hline & \multicolumn{2}{|c|}{ Number (percentage) } & \\
\hline Serious medical error & $100(63.3)$ & $25(15.8)$ & Gamma $=0.848$ \\
\hline Minor medical error & $79(51.3)$ & $26(16.9)$ & $P$ value $<0.001$ \\
\hline
\end{tabular}

TABle 4: The interns' experience of medical error disclosure and management of the medical error.

\begin{tabular}{|c|c|c|}
\hline Issue & Report & Number (percentage) \\
\hline \multirow{2}{*}{ Medical error $\left(n^{*}=107\right)$} & Yes & $73(68.2)$ \\
\hline & No & $34(31.8)$ \\
\hline \multirow{2}{*}{ Minor medical error $(n=58)$} & Yes & $37(63.8)$ \\
\hline & No & $21(36.2)$ \\
\hline \multirow{2}{*}{ Serious medical error $(n=49)$} & Yes & $36(73.5)$ \\
\hline & No & $13(26.5)$ \\
\hline \multirow{2}{*}{ Proper management of the medical error and adverse effects of the error } & Yes & $49(47.1)$ \\
\hline & No & $55(52.9)$ \\
\hline \multirow{2}{*}{ Found the cause of the medical error } & Yes & $44(41.1)$ \\
\hline & No & $63(58.9)$ \\
\hline
\end{tabular}

*Number of contributors who answered the question.

are found to be among the factors that could be the causes of not reporting medical errors (Tables 5 and 6).

More than three-quarters $(73(75.3 \%))$ of the interns asserted that they did not encounter any serious consequences for not reporting an error. However, 8 (8.2\%) said that they faced moral and psychological issues, and 15 $(15.5 \%)$ had received a serious warning. Furthermore, more than half of the participants $(54.5 \%)$ reported that no serious problem occurred for their patients because of not reporting MEs, though more severe consequences of not reporting the errors such as mortality (25.7\%), severe morbidity (18.8\%), and delayed discharge (1\%) were also among the interns' experiences in this regard (Table 7).

The interns responded to the scenarios at the end of the questionnaire, in which a fault in the first scenario resulted in major consequences, and the second is a minor error. In response to the first scenario, 91 students (71.1\%) mentioned that they would report the error, and 37 (28.9\%) preferred not to report the error. Twenty $(23.8 \%)$ of the interns said that they would report the error to the attending physician, $48(57.1 \%)$ to resident physicians, and $15(17.9 \%)$ to the patients and their families. In response to the second scenario, $105(73.9 \%)$ said that they would report the fault, and $35(24.6 \%)$ said they would not. Twenty-five (20\%) mentioned that they would report the error to the attending physician, 42 (33.6\%) to resident physicians, and $29(23.2 \%)$ to the patients and their families. Moreover, 29 (23.2\%) of the interns said that they would compensate the error without telling anyone (Table 8).

\section{Discussion}

Nearly $70 \%$ and $90 \%$ of the participants of this study have mentioned that they had encountered at least one serious and minor ME, respectively. They noticed that MEs could be because of the shortage of workforce and extreme working hours. They also believed that other causes such as lack of experience, education, training, and inappropriate support could increase the errors. Previous studies also highlighted that extreme working hours and burnout have a significant impact on reducing job performance and can be a severe risk factor for MEs $[43,44]$. Moreover, poor physical and mental health, lack of experience and training, inadequate supervision, and lack of appropriate restoring of system failures are among the common factors contributing to MEs $[11,45]$.

MEs are unavoidable and affect the patients, treating physicians, and nurses, as well as medical institutions. Current evidence shows that the system failures are the leading causes of MEs; however, human errors are common and usually underreported in the clinical practice [45-47]. In this regard, designing necessary methods that are protected from accidental errors is required to build a reliable healthcare system. Moreover, recognizing, managing, and learning from the situation caused by the ME are among crucial steps towards ME prevention, patient safety improvement, and quality care enhancement [48]. In this regard, facing and disclosing MEs is a challenging task for healthcare personnel [47]. To improve the rate of ME disclosure, the next generation of physicians must be properly prepared to disclose the errors.

The rate of ME disclosure has been increasing since the publication of "To Err is Human" as it shattered the sentiments that aligned with the physicians' paternalism [49]. Furthermore, this progress could be because of the increased public education and demands as well as the development of patient safety and quality services [50]. Still, the public does not acknowledge these improvements and feels that the MEs are inadequately disclosed to them [51]. They believe that the MEs should be disclosed to them irrespective of the severity of the harm [52]. Consistently, the patients'Bill of Rights 
TABLE 5: Reasons for disclosing or not disclosing medical errors.

\begin{tabular}{|c|c|c|c|c|c|c|}
\hline Questions & $\begin{array}{l}\text { Completely } \\
\text { agree }\end{array}$ & Agree & $\begin{array}{l}\text { Somehow } \\
\text { agree }\end{array}$ & Disagree & $\begin{array}{l}\text { Completely } \\
\text { disagree }\end{array}$ & $\begin{array}{l}\text { Mean } \\
\text { score }\end{array}$ \\
\hline $\begin{array}{l}\text { Patients have the right to be informed about medical } \\
\text { errors }\end{array}$ & $26(16.2)$ & $\begin{array}{c}52 \\
(32.5) \\
\end{array}$ & $61(38.1)$ & $9(5.6)$ & $12(7.5)$ & 3.44 \\
\hline $\begin{array}{l}\text { Medical error disclosure helps the physicians to keep } \\
\text { their professional integrity }\end{array}$ & 35 (21.9) & $64(40)$ & $43(26.9)$ & $11(6.9)$ & $7(4.4)$ & 3.68 \\
\hline $\begin{array}{l}\text { Medical error disclosure could reverse the adverse effect } \\
\text { of the error }\end{array}$ & $26(16.2)$ & $\begin{array}{c}59 \\
(36.9)\end{array}$ & $45(28.1)$ & $20(12.5)$ & $9(5.6)$ & 3.45 \\
\hline $\begin{array}{l}\text { Medical error disclosure is a sign of physicians' } \\
\text { consciousness and morality }\end{array}$ & $3(1.9)$ & $\begin{array}{c}66 \\
(41.2) \\
\end{array}$ & $41(25.6)$ & $12(7.4)$ & $1(0.6)$ & 3.81 \\
\hline Medical error could affect both physicians and patients & $43(26.9)$ & $\begin{array}{c}73 \\
(45.6)\end{array}$ & $33(20.6)$ & $8(5)$ & $2(1.2)$ & 3.92 \\
\hline
\end{tabular}

TABLE 6: Reasons for not disclosing medical errors.

\begin{tabular}{|c|c|c|c|c|c|c|}
\hline Questions & $\begin{array}{l}\text { Completely } \\
\text { agree }\end{array}$ & Agree & $\begin{array}{l}\text { Somehow } \\
\text { agree }\end{array}$ & Disagree & $\begin{array}{l}\text { Completely } \\
\text { disagree }\end{array}$ & $\begin{array}{l}\text { Mean } \\
\text { score }\end{array}$ \\
\hline There is no need of disclosing the error as it is inevitable & $23(14.4)$ & $\begin{array}{c}27 \\
(16.9)\end{array}$ & $39(24.4)$ & $49(30.6)$ & $21(13.1)$ & 3.11 \\
\hline $\begin{array}{l}\text { The healthcare system should be blamed for any medical } \\
\text { error, not the physician }\end{array}$ & $7(4.4)$ & $\begin{array}{c}12 \\
(7.5)\end{array}$ & $48(30)$ & $44(27.5)$ & $48(30)$ & 3.71 \\
\hline $\begin{array}{l}\text { Physician should only apologize the patients after the } \\
\text { occurrence of the medical error, and no further action is } \\
\text { needed }\end{array}$ & $8(5)$ & $29(18)$ & $40(25)$ & $63(39.4)$ & $15(9.4)$ & 3.30 \\
\hline Medical error disclosure could lead to litigation of physicians & $30(18.8)$ & $\begin{array}{c}66 \\
(41.2)\end{array}$ & $47(29.4)$ & $11(6.9)$ & $5(3.1)$ & 2.33 \\
\hline $\begin{array}{l}\text { The physicians might lose their respect and esteem because of } \\
\text { medical error disclosure }\end{array}$ & $21(13.1)$ & $\begin{array}{c}46 \\
(28.8) \\
\end{array}$ & $43(26.9)$ & $35(21.9)$ & $13(8.1)$ & 2.82 \\
\hline $\begin{array}{l}\text { The patients and their families might dangerously overreact to } \\
\text { the problem }\end{array}$ & $68(42.5)$ & $\begin{array}{c}54 \\
(33.8)\end{array}$ & $33(20.6)$ & $3(1.9)$ & $1(0.6)$ & 1.83 \\
\hline $\begin{array}{l}\text { The physicians might encounter with penalties if they report } \\
\text { their errors }\end{array}$ & $49(30.6)$ & $\begin{array}{c}52 \\
(32.5)\end{array}$ & $29(18.1)$ & $19(11.9)$ & $10(6.2)$ & 2.30 \\
\hline The patients cannot properly understand the medical error & $59(36.9)$ & $\begin{array}{c}49 \\
(30.6)\end{array}$ & $36(22.5)$ & $13(8.1)$ & $3(1.9)$ & 2.07 \\
\hline $\begin{array}{l}\text { Lack of communication skills could be a cause for not } \\
\text { reporting medical errors }\end{array}$ & $12(7.5)$ & $\begin{array}{c}23 \\
(14.4)\end{array}$ & $45(28.1)$ & $59(36.9)$ & 19 (11.9) & 3.28 \\
\hline $\begin{array}{l}\text { Lack of knowledge could be a cause for not reporting medical } \\
\text { errors }\end{array}$ & $15(9.4)$ & $\begin{array}{c}29 \\
(18.1) \\
\end{array}$ & $57(35.6)$ & $46(28.8)$ & $13(8.1)$ & 3.08 \\
\hline $\begin{array}{l}\text { There is no need for medical error disclosure; however, it } \\
\text { must be compensated }\end{array}$ & $40(25)$ & $\begin{array}{c}37 \\
(23.1)\end{array}$ & $44(27.5)$ & $34(23.1)$ & $5(3.1)$ & 2.54 \\
\hline
\end{tabular}

TABLE 7: Consequences and penalties after students' failure to report a medical error.

\begin{tabular}{lccc}
\hline Consequences for patients & Number (percentage) & Penalties for students & Number (percentage) \\
\hline Nothing happened & $55(54.5)$ & Nothing happened & $73(75.3)$ \\
Mortality & $26(25.7)$ & Feeling guilty & $8(8.2)$ \\
Severe morbidity & $19(18.8)$ & Serious warning & $15(15.5)$ \\
Delayed discharge & $1(1)$ & Persuasion & $1(1)$ \\
\hline
\end{tabular}

TABle 8: Participant's response to scenarios.

\begin{tabular}{|c|c|c|c|c|}
\hline Issue & $\begin{array}{c}\text { Not report } \\
\text { Number } \\
\text { (percentage) }\end{array}$ & $\begin{array}{c}\text { Report to the attending physician } \\
\text { Number (percentage) }\end{array}$ & $\begin{array}{l}\text { Report to the resident } \\
\text { Number (percentage) }\end{array}$ & $\begin{array}{c}\text { Report to the patient } \\
\text { Number } \\
\text { (percentage) }\end{array}$ \\
\hline \multirow{2}{*}{$\begin{array}{l}\text { Scenario results in major damage } \\
\text { Scenario results in minor } \\
\text { damage }\end{array}$} & $37(28.9)$ & $20(23.8)$ & $48(57.1)$ & 15 (17.9) \\
\hline & 35 (24.6) & $25(20)$ & $42(33.6)$ & $29(23.2)$ \\
\hline
\end{tabular}


asserts that the patients have the right of being informed of an error. As in many cases, ME disclosure will increase the opportunity for improving treatment outcomes. Most of the patients prefer to be made aware of almost all events and possible errors in a transparent manner, no matter what is the extent of MEs.

Currently, different guidelines are available for $\mathrm{ME}$ disclosure and giving information about the MEs to the patients. Some suggest that the patients should be informed when the error is serious and harmful (irreversible and improperly compensated errors); conversely, some propose that all the errors must be addressed to patients, even minor and unintended mistakes $[27,50]$. Presently, most healthcare personnel have accepted the standards that imply ME disclosure of even minor, unserious, and unintentional faults.

In the present study, more than four-fifths of the medical interns reported that they will disclose both minor and serious MEs ( $83 \%$ and $82 \%$, respectively). However, it seems that these numbers decrease in clinical practice as about half of the participants refused to answer the questions that evaluate their experiences on this matter, during clinical clerkship. Moreover, among those who answered the items, only $63 \%$ have disclosed minor errors and $73 \%$ have disclosed serious errors.

The interns' refusal to answer the questions that evaluate their ME disclosure in the clinical practice and the decreased rate of ME disclosure during the practice could be because of feelings of disappointment, guilt, distress, and sense of incompetence, as mentioned by previous investigations $[53,54]$.

The present study showed the female interns and the interns who had stricter religious adherence are more tended to report MEs, while no significant association was found between the marital status and the frequency of the error disclosure. Previous studies mentioned that the frequency does not associate with gender or religious beliefs; however, an association was found between marital status and ME disclosure rate $[5,50]$. These variances may be because of the different statistical society, population number, time, and environment of the studies. Our results also demonstrated that the interns who report minor errors are more tended to report the serious MEs.

The participants of the present study typically prefer to report minor and serious MEs to the ward resident physicians. They mentioned that they would not report the errors to the institution's management center, while in case of any $\mathrm{ME}$, the management should be notified to be able to legally and emotionally support the trainees. This lack of trust in the authorities might be due to the system's incompetency in providing physical, mental, emotional support for the interns, specifically in developing countries. In contrast to these results, previous studies reported that some physicians prefer to report the error to the management and to hide it from their colleagues [50].

In the present study, the interns thought that the MEs should be disclosed because it could help the physicians to hold their responsibilities and professional integrity and maintain their honesty, sincerity, and morality during practice. The interns have also been disclosing the MEs to improve patients' autonomy, increase the chance of reversing the adverse effects of the error, recover the patientphysician relationship, and prevent future malpractice liability. There was no significant difference between genders regarding the assertation of these ideas. Consistently, previous investigations have mentioned that the potential benefits of ME disclosure for both parties could be the timely diagnosis of the adverse events, improved patient-physician relationship, better compensation of the adverse outcomes, reduced emotional distresses, and decreased chance of litigation $[49,55]$.

In contrast to the above findings, our results also showed that some of the participants thought that reporting MEs would not be necessary as they are inevitable and system failures cause most of them. Possibility of being punished by superiors, loss of credibility and respect among colleagues, facing institutional penalties, encountering the patients' inappropriate reaction, and litigation were described to be the physicians' reasons for not reporting the errors. The interns also thought that lack of communication skills and knowledge could result in these fears and not reporting MEs. In these cases, female interns were more tended to have these attitudes, compared to male interns. Other studies mentioned that lack of detailed guidelines and education, lack of positive feedback from superiors, fear of being reprimanded, legal charges, absence of communication skills and knowledge, coworkers' reactions, the possibility of loss of respect and status, and also uncertainty about patients' reactions are the main barriers of $\mathrm{ME}$ disclosure [45, 56-58].

In Iranian society, people care about others thinking about them. Teaching faculty and senior physician, as reference individuals, play out an influential role in the formation process of attitudes, decisions, and actions within the clinical environment. They form the bases for and standards against in which their subordinates' acts are judged. Their view of error reporting can affect the behavior of the subordinates including interns. When an intern reports an error, he or she is seen as acting against the seniors. Healthcare educational policymakers need to develop a commitment-based management rather than a hierarchical, control-based punitive management system to identify the majority of medical errors and risk factors which help avoiding preventable adverse events.

Disclosure of errors presents enormous challenges for the interns as well as the physicians. Medical institutions should develop guidelines and instructions to help treat physicians to report the errors. They should also encourage the physicians in this regard by providing them appropriate support and insurances, instead of punishing, disgracing, or rejecting them. The institutions should not blame the physicians alone as in most cases, the MEs are caused by the healthcare system failures [45]. ME disclosure education should also be a part of the trainee's curriculum as our study showed that most of the interns believed that they need more courses regarding the $\mathrm{ME}$ disclosure. The presence of role models to medical trainees can be an effective factor on improving the competency in ME disclosure through providing a passive, experiential method of learning for these individuals. One of the problems in this area in the context 
of our study is the definition of many different roles for physicians in charge of medical education in a clinical setting. Obviously, it is very difficult to play multiple roles at the same time.

Furthermore, the result of our research and previous studies showed that emotional, psychological, and cultural issues are major contributing factors of disclosing errors, which should be evaluated in future studies [39]. Healthcare providers must understand the complexity of medical errors and seek to reduce the frequency of mistakes by recognizing the etiology and planning practical approaches.

Our study has some limitations. One of the most important weaknesses of our study is the sampling method. Although the response rate was quite acceptable, as the present investigation was done in teaching hospitals of Shiraz Medical School, the results might not be applicable to trainees in other areas. The study could have been done on greater scales in order to achieve more comprehensive findings. Besides, our investigation is a descriptive study that focuses on descriptive analysis of the situation and objects; however, in order to find the actual attitudes of medical interns regarding the disclosure of errors, qualitative research studies could also be useful.

\section{Conclusion}

Adequate mental, legal, and financial supports could encourage medical interns and physicians to report a ME. The most significant barriers to disclose MEs are fear of being legally and financially punished or being rejected and disgraced. Policymakers and authorities should implement strategies to support healthcare professionals after reporting an error. These goals could be achieved by positive advertisements and increasing education and research on this matter.

\section{Abbreviations}

ME: Medical error

INR: International normalized ratio

PT: Prothrombin time

MRI: Magnetic resonance imaging.

\section{Data Availability}

The datasets used and/or analyzed during the current study are available from the authors upon reasonable request.

\section{Ethical Approval}

The study protocol was approved by the Medical Ethics Committee of Shiraz University of Medical Sciences, and the participants voluntarily involved in this study. They were assured that no personal information is required and their data would be kept confidential.

\section{Consent}

All authors approved the paper and agreed to its submission and publishing in this journal.

\section{Conflicts of Interest}

The authors declare that there are no conflicts of interest regarding the publication of this paper.

\section{Authors' Contributions}

SE investigated the study, supervised the study, administered the project, and reviewed and edited the article. SZT validated the study and reviewed and edited the article. FK visualized the study, developed the methodology, and reviewed and edited the article. AE reviewed and edited the article, curated the data, contributed to software, and performed formal analysis.

\section{Acknowledgments}

This study was sponsored by the research deputy of the Faculty of Medicine from research project no. 5551, Shiraz University of Medical Sciences, Shiraz, Iran.

\section{Supplementary Materials}

Questionnaire and other data related to the investigation can be provided upon request. (Supplementary Materials)

\section{References}

[1] E. D. Grober and J. M. A. Bohnen, "Defining medical error," Canadian Journal of Surgery, vol. 48, no. 1, pp. 39-44, 2005.

[2] J. Reason, Human Error, Cambridge University Press, Cambridge, UK, 1990.

[3] L. L. Leape, "Error in medicine," The Journal of the American Medical Association, vol. 272, no. 23, pp. 1851-1857, 1994.

[4] N. Rezayi and M. Abbasi, "Criminological investigation in medical criminal errors," Iranian Journal of Medical Law, vol. 6, no. 22, pp. 85-112, 2012.

[5] S. Biranvand, "Disclosing medical errors and its relationship to disclosure of actual and hypothetical errors: nursing staff's attitude," Iranian Journal of Medical Ethics and History of Medicine, vol. 7, no. 1, pp. 53-64, 2014.

[6] G. A. Assiri, N. A. Shebl, M. A. Mahmoud et al., "What is the epidemiology of medication errors, error-related adverse events and risk factors for errors in adults managed in community care contexts? A systematic review of the international literature," BMJ open, vol. 8, no. 5, Article ID e019101, 2018.

[7] S. Vaziri, F. Fakouri, M. Mirzaei, M. Afsharian, M. Azizi, and M. Arab-Zozani, "Prevalence of medical errors in Iran: a systematic review and meta-analysis," BMC Health Services Research, vol. 19, no. 1, p. 622, 2019.

[8] M. A. Makary and M. Daniel, "Medical error-the third leading cause of death in the US," BMJ, vol. 353, Article ID i2139, 2016.

[9] A. F. Hannawa, Y. Shigemoto, and T. D. Little, "Medical errors: disclosure styles, interpersonal forgiveness, and outcomes," Social Science \& Medicine, vol. 156, pp. 29-38, 2016.

[10] M. Khammarnia and F. Setoodehzadeh, "Medical error as a challenge in Iran's health system," Health Scope, vol. 6, no. 1, Article ID e61597, 2017.

[11] A. Bari, R. A. Khan, and A. W. Rathore, "Medical errors; causes, consequences, emotional response and resulting 
behavioral change," Pakistan Journal of Medical Sciences, vol. 32, no. 3, pp. 523-528, 2016.

[12] M. P. Tully, D. M. Ashcroft, T. Dornan, P. J. Lewis, D. Taylor, and V. Wass, "The causes of and factors associated with prescribing errors in hospital inpatients," Drug Safety, vol. 32, no. 10, pp. 819-836, 2009.

[13] J. D. Waldman and H. L. Smith, "Strategic planning to reduce medical errors: part I-diagnosis," The Journal of Medical Practice Management, vol. 27, no. 4, pp. 230-236, 2012.

[14] L. L. Leape, "A systems analysis approach to medical error," Journal of Evaluation in Clinical Practice, vol. 3, no. 3, pp. 213-222, 1997.

[15] M. S. Leonard, "Patient safety and quality improvement: medical errors and adverse events," Pediatrics in Review, vol. 31, no. 4, pp. 151-158, 2010.

[16] S. Grepperud, "Medical errors: responsibility and informal penalties," Harvard Health Policy Review, vol. 5, no. 1, pp. 89-95, 2004.

[17] A. Smadi, D. Abdullah Wardat, and M. Al-Khawaldeh, "Medical errors and physicians liability between Islamic regulations and law," Journal of Islamic Studies and Culture, vol. 7, no. 2, pp. 1-3, 2019.

[18] S. Middleton and M. D. Buist, "Medical-setting deaths and the coroner: laws, penalties and guidelines," Medical Journal of Australia, vol. 201, no. 11, pp. 679-681, 2014.

[19] A. F. Merry, "How does the law recognize and deal with medical errors?" Journal of the Royal Society of Medicine, vol. 102 , no. 7, pp. 265-271, 2009.

[20] T. J. Silber and M. A. Hilliard, "Iatrogenesis: ethical and legal aspects," Adolescent Medicine: State of the Art Reviews, vol. 22, no. 2, p. 289, 2011.

[21] A. Matlow, P. Stevens, C. Harrison, and R. M. Laxer, "Disclosure of medical errors," Pediatric Clinics of North America, vol. 53, no. 6, pp. 1091-1104, 2006.

[22] S. L. Stokes, A. W. Wu, and P. J. Pronovost, "Ethical and practical aspects of disclosing adverse events in the emergency department," Emergency Medicine Clinics of North America, vol. 24, no. 3, pp. 703-714, 2006.

[23] D. Hilfiker, "Facing our mistakes," New England Journal of Medicine, vol. 310, no. 2, pp. 118-122, 1984.

[24] T. H. Gallagher and W. Levinson, "Disclosing harmful medical errors to patients," Archives of Internal Medicine, vol. 165, no. 16, pp. 1819-1824, 2005.

[25] A. F. Hannawa, H. Beckman, K. M. Mazor, N. Paul, and J. V. Ramsey, "Building bridges: future directions for medical error disclosure research," Patient Education and Counseling, vol. 92, no. 3, pp. 319-327, 2013.

[26] J. C. Moskop, J. M. Geiderman, C. D. Hobgood, and G. L. Larkin, "Emergency physicians and disclosure of medical errors," Annals of Emergency Medicine, vol. 48, no. 5, pp. 523-531, 2006.

[27] K. M. Mazor, G. W. Reed, R. A. Yood, M. A. Fischer, J. Baril, and J. H. Gurwitz, "Disclosure of medical errors," Journal of General Internal Medicine, vol. 21, no. 7, pp. 704-710, 2006.

[28] M. C. Newman, "The emotional impact of mistakes on family physicians," Archives of Family Medicine, vol. 5, no. 2, pp. 71-75, 1996.

[29] J. O'Shaughnessy, "Disclosing the errors of other physicians," Annals of Emergency Medicine, vol. 49, no. 6, pp. 826-827, 2007.

[30] A. Ranaei, H. A. Gorji, A. Aryankhesal, and M. Langarizadeh, "Investigation of medical error-reporting system and reporting status in Iran in 2019," Journal of Education and Health Promotion, vol. 9, p. 272, 2020.
[31] T. H. Gallagher, "Patients' and physicians' attitudes regarding the disclosure of medical errors," JAMA, vol. 289, no. 8, pp. 1001-1007, 2003.

[32] B. Perez, S. A. Knych, S. J. Weaver et al., "Understanding the barriers to physician error reporting and disclosure," Journal of Patient Safety, vol. 10, no. 1, pp. 45-51, 2014.

[33] R. Sirriyeh, R. Lawton, P. Gardner, and G. Armitage, "Coping with medical error: a systematic review of papers to assess the effects of involvement in medical errors on healthcare professionals' psychological well-being," BMJ Quality and Safety, vol. 19, no. 6, p. e43, 2010.

[34] D. Soydemir, S. Seren Intepeler, and H. Mert, "Barriers to medical error reporting for physicians and nurses," Western Journal of Nursing Research, vol. 39, no. 10, pp. 1348-1363, 2017.

[35] J. Firth-Cozens, "Barriers to incident reporting," Quality and Safety in Health Care, vol. 11, no. 1, p. 7, 2002.

[36] T. Manser and S. Staender, "Aftermath of an adverse event: supporting health care professionals to meet patient expectations through open disclosure," Acta Anaesthesiologica Scandinavica, vol. 49, no. 6, pp. 728-734, 2005.

[37] J. Kalra, K. L. Massey, and A. Mulla, "Disclosure of medical error: policies and practice," Journal of the Royal Society of Medicine, vol. 98, no. 7, pp. 307-309, 2005.

[38] L. Stroud, B. M. Wong, E. Hollenberg, and W. Levinson, "Teaching medical error disclosure to physicians-in-training: a scoping review," Academic Medicine: Journal of the Association of American Medical Colleges, vol. 88, no. 6, pp. 884-892, 2013.

[39] A. A. White, T. H. Gallagher, M. J. Krauss et al., "The attitudes and experiences of trainees regarding disclosing medical errors to patients," Academic Medicine, vol. 83, no. 3, pp. 250-256, 2008.

[40] A. Vazin and M. Fereidooni, "Determining frequency of prescription, administration and transcription errors in internal intensive care unit of Shahid Faghihi Hospital in Shiraz with direct observation approach," Iranian Journal of Pharmaceutical Sciences, vol. 8, no. 3, pp. 189-194, 2012.

[41] H. Northcott, L. Vanderheyden, J. Northcott et al., "Perceptions of preventable medical errors in Alberta, Canada," International Journal for Quality in Health Care: Journal of the International Society for Quality in Health Care, vol. 20, no. 2, pp. 115-122, 2008.

[42] R. M. Lamb, D. M. Studdert, R. M. J. Bohmer, D. M. Berwick, and T. A. Brennan, "Hospital disclosure practices: results of a national survey," Health Affairs, vol. 22, no. 2, pp. 73-83, 2003.

[43] T. D. Shanafelt, C. M. Balch, G. Bechamps et al., "Burnout and medical errors among American surgeons," Annals of Surgery, vol. 251, no. 6, pp. 995-1000, 2010.

[44] S. Ebrahimi and F. Atazadeh, "Medical students' occupational burnout and its relationship with professionalism," Journal of advances in medical education \& professionalism, vol. 6 , no. 4, pp. 162-167, 2018.

[45] A. Mansouri, A. Ahmadvand, M. Hadjibabaie et al., "A review of medication errors in Iran: sources, underreporting reasons and preventive measures," Iranian Journal of Pharmaceutical Research: IJPR, vol. 13, no. 1, pp. 3-17, 2014.

[46] H. Singh, E. J. Thomas, L. A. Petersen, and D. M. Studdert, "Medical errors involving trainees," Archives of Internal Medicine, vol. 167, no. 19, pp. 2030-2036, 2007.

[47] A. W. Wu, "Do house officers learn from their mistakes?" The Journal of the American Medical Association, vol. 265, no. 16, pp. 2089-2094, 1991. 
[48] T. A. Brennan, L. L. Leape, N. M. Laird et al., "Incidence of adverse events and negligence in hospitalized patients," New England Journal of Medicine, vol. 324, no. 6, pp. 370-376, 1991.

[49] S. L. Teti, K. Ennis-Durstine, and T. J. Silber, "Etiology and manifestations of iatrogenesis in pediatrics," AMA Journal of Ethics, vol. 19, no. 8, pp. 783-792, 2017.

[50] R. E. Adams and J. A. Boscarino, "A community survey of medical errors in New York," International Journal for Quality in Health Care, vol. 16, no. 5, pp. 353-362, 2004.

[51] R. J. Blendon, C. M. DesRoches, M. Brodie et al., "Views of practicing physicians and the public on medical errors," New England Journal of Medicine, vol. 347, no. 24, pp. 1933-1940, 2002.

[52] C. Hobgood, "Parental preferences for error disclosure, reporting, and legal action after medical error in the care of their children," Pediatrics, vol. 116, no. 6, pp. 1276-1286, 2005.

[53] A. A. White and T. Gallagher, "After the apology-coping and recovery after errors," AMA Journal of Ethics, vol. 13, no. 9, pp. 593-600, 2011.

[54] C. Hobgood, A. Hevia, J. H. Tamayo-Sarver, B. Weiner, and R. Riviello, "The influence of the causes and contexts of medical errors on emergency medicine residents??? responses to their errors: an exploration," Academic Medicine, vol. 80, no. 8, pp. 758-764, 2005.

[55] J. P. Straumanis, "Disclosure of medical error: is it worth the risk?" Pediatric Critical Care Medicine, vol. 8, no. 2, 2007.

[56] L. Stroud, J. McIlroy, and W. Levinson, "Skills of internal medicine residents in disclosing medical errors: a study using standardized patients," Academic Medicine, vol. 84, no. 12, pp. 1803-1808, 2009.

[57] H. Kouhestani and N. Baghcheghi, "Refusal in reporting medication errors from the viewpoints of nursing students in arak university of medical sciences," Iranian Journal of Medical Education, vol. 8, no. 2, 2008.

[58] S. N. Weingart, A. N. Ship, and M. D. Aronson, "Confidential clinician-reported surveillance of adverse events among medical inpatients," Journal of General Internal Medicine, vol. 15, no. 7, pp. 470-477, 2000. 